\title{
Author credentials
}

Affiliations

Stepanov Kirill - engineer of Federal State Budgetary Scientific Institution "Federal Scientific Agroengineering Center VIM", Russia, Moscow, e-mail: 89999878895@mail.ru.

Ivanov Maxim - engineer of Federal State Budgetary Scientific Institution "Federal Scientific Agroengineering Center VIM”, Russia, Moscow, e-mail: maks.ivanov.1992@mail.ru.

Kryukov Michael - leading specialist of Federal State Budgetary Scientific Institution "Federal Scientific Agroengineering Center VIM”, Russia, Moscow, e-mail: krumil52@mail.ru.

Поступила в редакцию (Received): 20.07.2020 Принята к публикации (Accepted): 21.08.2020

УДК 635.21

DOI: $10.35887 / 2305-2538-2020-4-26-33$

\section{РЕЗУЛЬТАТЫ ЭКСПЕРИМЕНТАЛЬНЫХ ИССЛЕДОВАНИЙ ВЫСАЖИВАЮЩЕГО АППАРАТА МИНИ КАРТОФЕЛЕСАЖАЛКИ}

\author{
${ }^{1}$ Бочкарев Антон Сергеевич \\ ${ }^{1}$ Ларюшин Николай Петрович \\ ${ }^{1}$ Кухарев Олег Николаевич \\ ${ }^{1}$ ФББОУ ВО «Пензенский государственный аграрный университет»
}

Реферат. Основным фактором, влияющим на урожайность картофеля, является площадь питания, определяемая равномерностью распределения клубней по дну бороздьл при посадке. Соблюдение равномерности распределения семенного материала является приоритетной задачей при конструировании сажалок. Обоснование оптимальных значений высаживающего аппарата с ограничителем раскатывания клубней по дну борозды осуществили с помощьюю многофакторного эксперимента. За критерий оптимизации процесса высадки принимали равномерность распределения клубней по дну борозды после посадки, под которой понимали процент высаженных клубней, фактическое расстояние между которыми не могло отличаться больше, чем в 0,8 - 1,2 раза от установленного на высаживающем аппарате. На основе априорного ранжирования были отобраны 8 факторов, которые в значительной мере влияют на эту характеристику. Определень оптимальные параметры: усилие прижатия катка к дну борозды - 14 - 26 H, диаметр катка - 115 - 155 мм, показатель кинематического режима - 0, - 1,1, которые обеспечивают равномерность распределения клубней по дну борозды после посадки не менее 86 \%.. Экспериментальный высаживающий аппарат исследован на почвенном канале. В результате эксперимента получень зависимости равномерности распределения клубней по дну борозды после посадки от усилия прижатия катка к дну борозды, диаметра катка, кинематического режима. Установлено, что при использовании экспериментального высаживающего аппарата с ограничителем скорости клубней с данными конструктивными параметрами повысится урожайность производимой культуры $и$ снизятся затрать на её производство.

Ключевые слова: картофель, мини картофелесажалка, многофакторный эксперимент, равномерность распределения клубней.

\section{EXPERIMENTAL RESEARCH RESULTS PLANTING APPARATUS AT MINI POTATO PLANTER}

${ }^{I}$ FSBEI HE "Penza State Agrarian University”

\author{
${ }^{1}$ Bochkarev Anton \\ ${ }^{1}$ Laryushin Nikolay \\ ${ }^{1}$ Kuharev Oleg
}

Abstract. The main factor affecting the yield of potatoes is the feeding area, determined by the uniform distribution of tubers along the bottom of the furrow during planting. The rationale for the 
optimal values of the planting apparatus with a limiter for rolling tubers along the bottom of the furrow was carried out using a multivariate experiment. The uniformity of the distribution of tubers along the bottom of the furrow after planting, which was understood as the \% of tubers planted, the actual distance between which could not differ more than 0,8 - 1,2 times from that installed on the planting apparatus, was taken as an optimization criterion. 8 factors that significantly affect this characteristic were selected based on a priori ranking. Optimum parameters: the pressing force of the skating rink to the bottom of the furrow is $14-26 \mathrm{~N}$, the diameter of the skating rink is $115-155 \mathrm{~mm}$, the kinematic index is 0, - 1.1, which ensure a uniform distribution of tubers along the bottom of the furrow after planting at least $86 \%$. were determined. The experimental planting apparatus was investigated on the soil channel. As a result of the experiment, the dependences of the uniform distribution of tubers along the bottom of the furrow after planting on the pressing force of the roller to the bottom of the furrow, the diameter of the roller, and the kinematic mode are obtained. It was established that when using an experimental planting apparatus with a tuber speed limiter with these design parameters, the yield of the produced crop will increase and the cost of its production will decrease.

Keywords: potato, mini potato planter, multivariate experiment, uniform distribution of tubers.

Введение. Посадка является наиболее значимой операцией в технологии производства, как для картофеля, так и для других сельскохозяйственных культур. На урожай особенно оказывают влияние климатические условия, среда обитания где произрастает культура, а также качественные показатели выполнения посадочных работ. Всё вышеперечисленное позволяет снизить затраты труда и уменьшить себестоимость получаемой продукции.

Высаживающие аппараты мини картофелесажалок, не в полной мере соответствуют агротехническим требованиям. Основным фактором, определяющим урожайность картофеля, считается равномерность распределения клубней по дну борозды. Именно этот фактор отвечает за формирование площади питания для картофеля. В связи с этим конструирование высаживающего аппарата картофелесажалки таким образом, чтобы улучшались качественные показатели посадки семян (равномерность распределения семян по длине рядка, глубина их заделки) является актуальной. В ФГБОУ ВО Пензенский ГАУ с этой целью разработан, изготовлен и испытан высаживающий аппарат с ограничителем раскатывания клубней. На конструкцию данного устройства подана заявка на патент.

Материалы и методы. Для улучшения качественных показателей посадки картофеля в ФГБОУ ВО Пензенский ГАУ разработан высаживающий аппарат с ограничителем раскатывания клубней картофеля по дну борозды после посадки, изображенный на рисунке 1.

При использовании экспериментального высаживающего аппарата получен следующий результат: исключено раскатывание клубней картофеля, при этом происходит уплотнение семян картофеля на дне борозды, кроме этого обеспечивается равномерная глубина заделки клубней картофеля, а также равномерное распределение их по дну борозды. Всё это в свою очередь даёт равномерное прорастание семян. В итоге все перечисленное выше улучшает качественные показатели посадки семян картофеля. Это в свою очередь приводит к увеличению урожайности возделываемой культуры.

Для экспериментов по определению равномерности распределения клубней картофеля по длине рядка с высаживающим аппаратом, с ограничителем раскатывания клубней по дну борозды после посадки использовали лабораторную установку, показанную на рисунке 2.

Эта установка включала в себя: канал в металлическом основании, заполненный почвой 3 с установленной в нем подвижной тележкой с приводом 12 и навеской 8. Экспериментальная установка (высаживающий аппарат с ограничителем раскатывания клубней) помещена на навеску 8 тележки 12. Приближает экспериментальные условия к реальным установка сошника 2 картофелесажалки на навеске 8 приводной тележки 12 с минимальным зазором между нижней кромкой сошника-бороздообразователя 2 и поверхностью посадки. Для поверхности посадки создан ровный участок почвы. Приводную тележку 12 через редуктор 4, цепную передачу, систему полиспастов и гибкий трос 5 приводил в движение электродвигатель 7. Последний с помощью цепных передач через многоступенчатый редуктор 6 приводил в движение ложечноэлеваторный транспортер. Включение и отключение установки осуществляет оператор, используя пульт 13. 


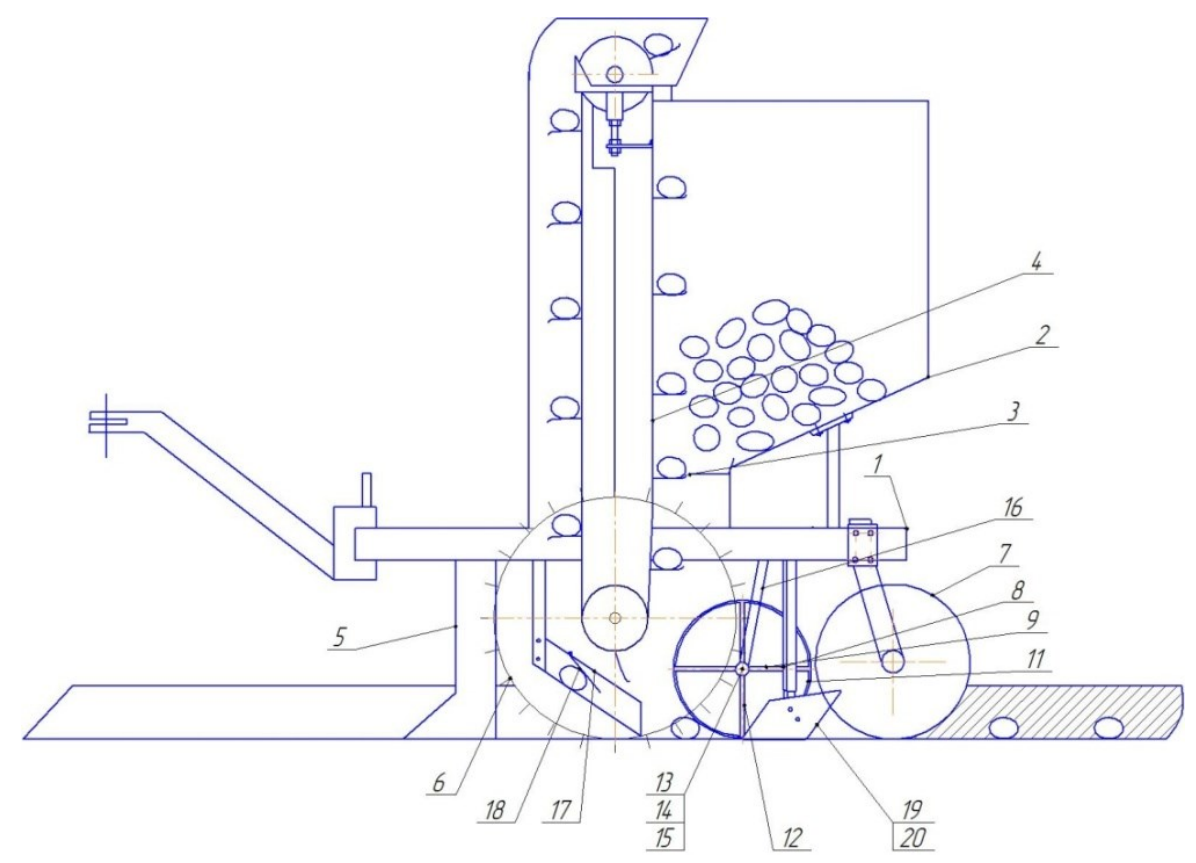

1 - рама; 2 - бункер; ковш-питатель; 4 -высаживающий аппарат; 5 - сошник-бороздообразователь; 6 -опорное колесо; 7 - бороздозакрыватель; 8 - ограничитель раскатывания клубней; 9 - каток;

10 - решетчатая поверхность цилиндра; 11 - обод; 12 - спица; 13 - ступица; 14 - подшипник скольжения; 15 - ось катка; 16 - пружинная стойка; 17 - желоб; 18 - ориентирующее устройство; 19, 20 - лапы-отвальчики.

Рисунок 1 - Схема картофелесажалки с высаживающим аппаратом с ограничителем раскатывания клубней:

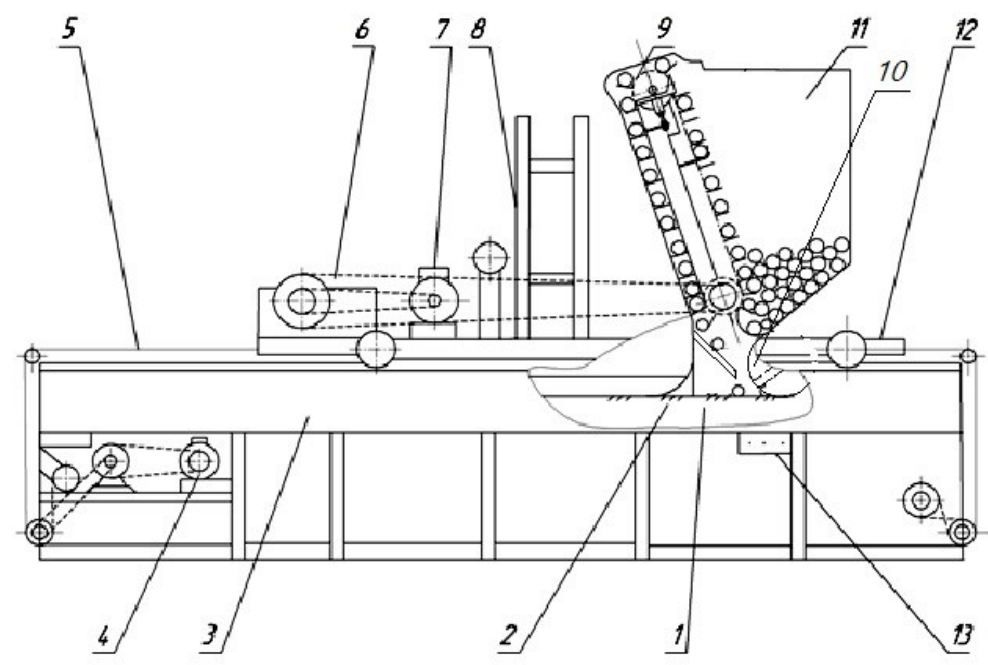

1 - почва; 2 - сошник-бороздообразователь; 3 - канал почвенный; 4 - редуктор; 5 - трос;

6 - цепная передача; 7 - мотор редуктор; 8- рама; 9 - цепочно-ложечный высаживающий аппарат; 10 - ограничитель раскатывания клубней; 11 -бункер; 12 -приводная тележка; 13 - пульт управления

Рисунок 2 - Общий вид лабораторной установки для изучения оптимальных конструктивно-кинематических параметров высаживающего аппарата с ограничителем раскатывания клубней по дну борозды 
Результаты и их обсуждение. За критерий оптимизации процесса высадки принимали \% высаженных клубней, фактическое расстояние между которыми отличалось не более, чем в 0,8 1,2 раза от установленного на высаживающем аппарате, характеризующего равномерность распределения клубней по дну борозды после посадки R.

Априорным ранжированием выбрали 8 основных факторов, которые в наибольшей степени влияют на равномерность распределения клубней по дну борозды после посадки. В начале зависимость факторов рассматривали линейно в программе Statistica 6.0, после чего был сделан вывод, что линейная зависимость неадекватно описывает данные. Стоит так же отметить, что экспериментальные исследования не позволяют учесть все факторы, определяющие равномерность распределения, поэтому были выбраны наиболее важные, по мнению авторов, на основании предварительно полученной информации.

Методика исследования предполагает отсеивающий эксперимент, для проведения которого использовали матрицу, учитывающую первоначально выделенные факторы путем случайного смешивания двух полуреплик. Обработка результатов отсеивающего эксперимента с помощью программы Statistica 6.0, выявилаосновные факторы, которые оказывают наибольшее влияние на равномерность распределения, при этом малозначимые факторы были отсеяны. Это в свою очередь уменьшило объём дальнейших исследований. Так же рассматривали зависимость факторов как линейную, после чего был сделан вывод, что линейная зависимость неадекватно описывает данные, ввиду того, что на графике функции множество точек выпадает из 95\% доверительного интервала. Факторы, влияющие на равномерность распределения картофеля по дну борозды после посадки, были выбраны следующие: $P$ - усилие прижатия катка к дну борозды, $D$ - диаметр катка, $\lambda$ - кинематический режим

После обработки результатов многофакторного эксперимента пришли к адекватной математической модели второго порядка, которая в закодированном виде описывала зависимость $R=f(P, D, \lambda)$ в следующем виде:

$$
\begin{gathered}
y=88,38+0,10300 x_{1}+0,82500 x_{2}-0,92400 x_{3}-2,42833 x_{1}^{2}-2,25833 x_{2}^{2}-1,3733 x_{3}^{2}+ \\
+\operatorname{m0} 0,87000 x_{1} x_{2}+0,75500 x_{1} x_{3}-0,78250 x_{2} x_{3}
\end{gathered}
$$

Дифференцируя уравнение (1) по переменным $x_{1}, x_{2}, x_{2}$ получаем систему состоящую из трёх дифференциальных уравнений (2):

$$
\left\{\begin{array}{c}
\frac{d y}{d x_{1}}=0,103+0,87 \cdot x_{2}+0,755 \cdot x_{3}-4,85666 \cdot x_{1}=0 \\
\frac{d y}{d x_{2}}=0,825+0,87 \cdot x_{1}-0,7825 \cdot x_{3}-2,74666 \cdot x_{2}=0 \\
\frac{d y}{d x_{3}}=-0,924+0,755 \cdot x_{1}-0,7825 \cdot x_{2}-2,74666 \cdot x_{3}=0
\end{array}\right.
$$

Решая данную систему уравнений, находим значения факторов, которые обеспечивают оптимальное значение равномерности распределения клубней картофеля по дну борозды после посадки. Они продемонстрированы в таблице 1.

Таблица 1 - Оптимальные значения факторов распределения клубней картофеля по дну борозды после посадки

\begin{tabular}{|l|c|c|}
\hline \multicolumn{2}{|c|}{ Факторы } & \multicolumn{2}{|c|}{ Оптимальные значения в виде } \\
\cline { 2 - 3 } & закодированном & раскодированном \\
\hline $\begin{array}{l}\text { P - усиление прижатия катка к дну } \\
\text { борозды, Н } \\
D-\text { диаметр катка, мм }\end{array}$ & 0,029 & 17,699 \\
\hline$\lambda$ - показатель кинематического режима & 0,439 & 136,007 \\
\hline
\end{tabular}

Для построения двумерного сечения поверхности отклика, которое характеризует величину усилия прижатия катка к дну борозды $\left(x_{1}\right)$ и показатель кинематического режима $\left(x_{3}\right)$, в уравнение (1) подставляем значение $x_{2}=0$. Получаем следующее уравнение (3):

$$
y=88,38+0,10300 x_{1}-0,92400 x_{3}-2,42833 x_{1}^{2}-1,3733 x_{3}^{2}+0,75500 x_{1} x_{3}
$$


Дифференцируя уравнение (3) по переменным $x_{1}$ и $x_{3}$ получаем систему, состоящую из двух дифференциальных уравнений:

$$
\left\{\begin{array}{l}
\frac{d y}{d x_{1}}=0,10300-4,8566 x_{1}+0,75500 x_{3}=0 \\
\frac{d y}{d x_{3}}=-0,92400+0,75500 x_{1}-2,7466 x_{3}=0
\end{array}\right.
$$

Решая уравнения системы (4), получаем в закодированном виде следующие координаты центра поверхности отклика:

$$
x_{1}=-0,032478, x_{3}=-0,345344
$$

Используя их для уравнения (3), получаем зависимость распределения клубней картофеля по дну борозды после посадки от Р - усилия прижатия к дну борозды и $\lambda$ - показателя кинематического режима (рисунок 3) в виде двумерного сечения поверхности отклика.

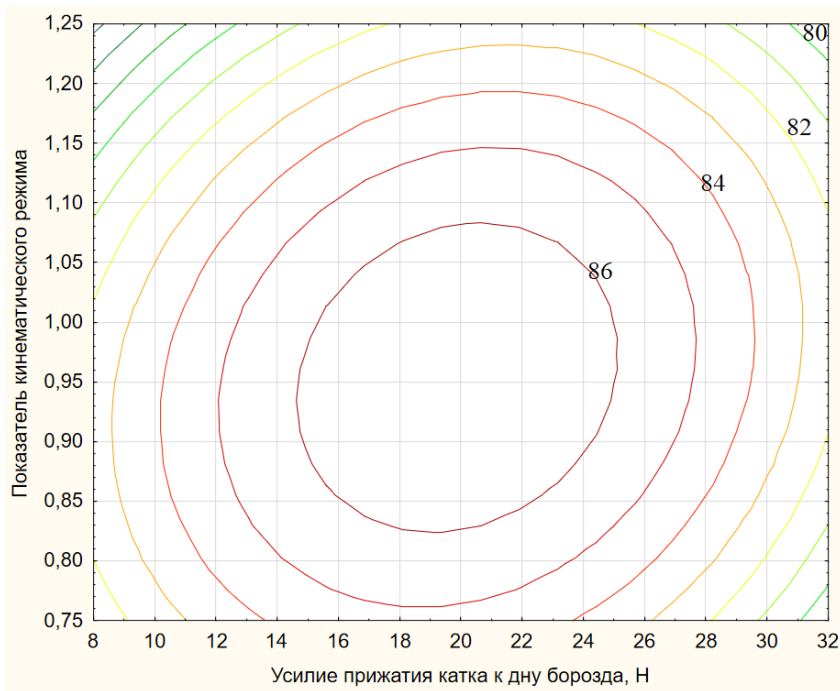

Рисунок 3 - Зависимость равномерности распределения клубней по дну борозды после посадки от усилия прижатия катка к дну борозды (Р) и показателя кинематического режима $(\lambda)$ в виде двумерного сечения поверхности отклика

Далее, по аналогии с предыдущими действиями, подставляем фактор $x_{3}$ с нулевым значением в выражение (3). Получаем следующее уравнение (5):

$$
y=88,38+0,10300 \cdot x_{1}+0,82500 \cdot x_{2}-2,42833 \cdot x_{1}^{2}-2,25833 \cdot x_{2}^{2}+0,87000 x_{1} x_{2}
$$

Дифференцируем уравнение по переменным $x_{1}$ и $x_{2}$. В итоге получаем систему из двух дифференциальных уравнений:

$$
\left\{\begin{array}{l}
\frac{d y}{d x_{1}}=0,103-4,85666 x_{1}+0,87 x_{2}=0 \\
\frac{d y}{d x_{2}}=0,825+0,87 x_{1}-4,51666 x_{2}=0
\end{array}\right.
$$

При решении системы уравнений (6), получили координаты центра поверхности отклика в закодированном виде:

$$
x_{1}=-0,011129, x_{2}=-0,180514
$$

Подставляя полученные значения в уравнение (3), строим двумерное сечение поверхности отклика, характеризующее зависимость распределения клубней картофеля по дну борозды после посадки от Р - усилия прижатия к дну борозды и $D$ - диаметра катка (рисунок 4).

Действуя по аналогии, подставляем в уравнение (3) приравненный к нулю фактор $x_{1}$ и получаем:

$$
y=88,38+0,82500 \cdot x_{2}-0,92400 \cdot x_{3}-2,25833 \cdot x_{2}^{2}-1,3733 \cdot x_{3}^{2}-0,78250 x_{2} x_{3}
$$




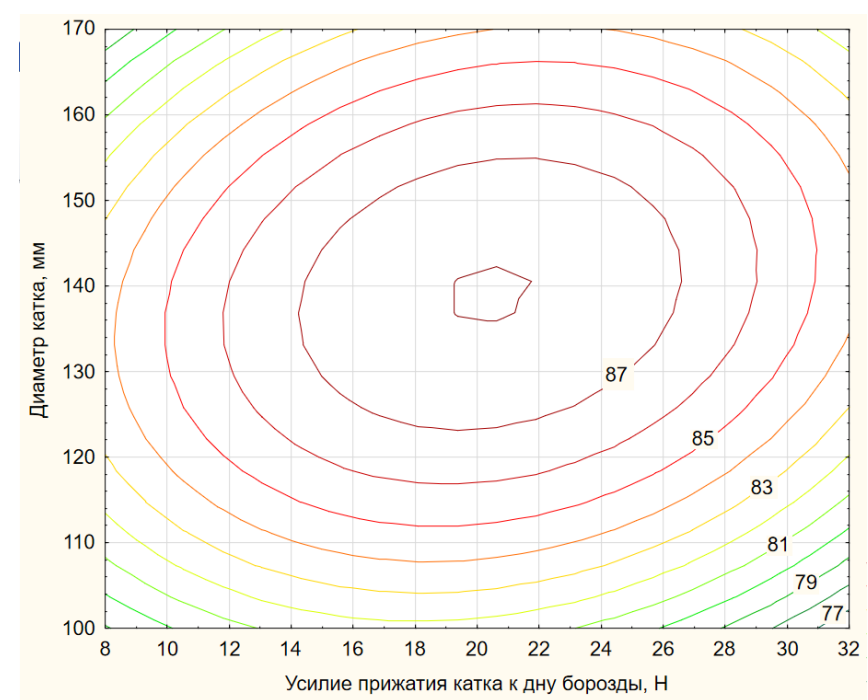

Рисунок 4 - Двумерное сечение поверхности отклика, характеризующее зависимость равномерности распределения клубней по дну борозды после посадки от усилия прижатия катка к дну борозды (P) и диаметра катка (D)

Дифференцируя уравнение (7) по переменным $x_{2}$ и $x_{3}$ получаем систему уравнений (8):

$$
\left\{\begin{array}{l}
\frac{d y}{d x_{2}}=-4,51666 x_{2}-0,78250 x_{3}-0,825=0 \\
\frac{d y}{d x_{3}}=-0,78250 x_{2}-2,7446 x_{3}-0,924=0
\end{array}\right.
$$

При решении системы уравнений (8), получаем в закодированном виде следующие координаты центра поверхности отклика:

$$
x_{2}=-0,130792, x_{3}=-0,299372 .
$$

Подставляя значения координат центра в уравнение (3), строим двумерное сечение поверхности отклика, характеризующее зависимость распределения клубней картофеля по дну борозды после посадки от Р - усилия прижатия к дну борозды и $\lambda$ - кинематического режима (рисунок 5).

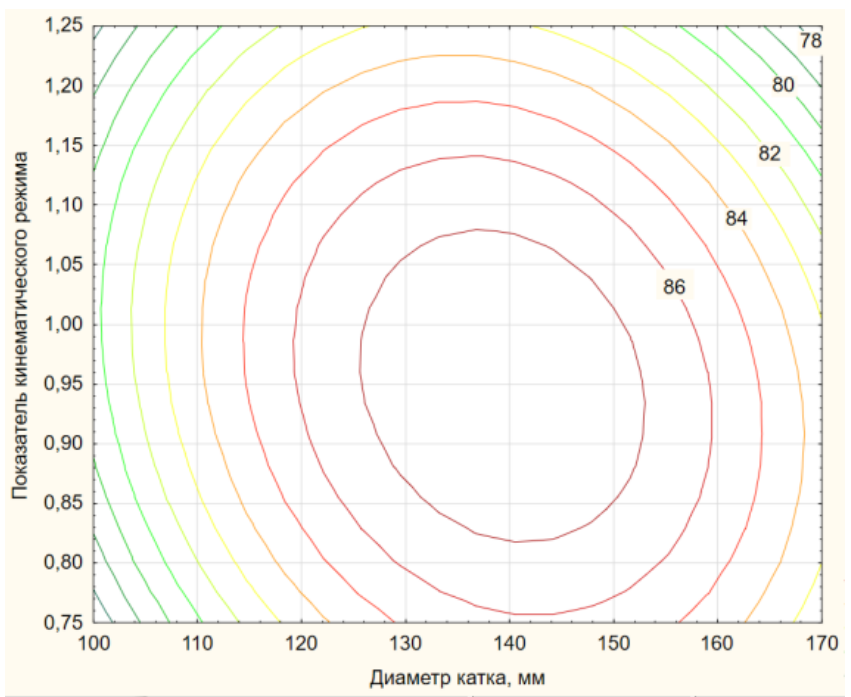

Рисунок 5 - Двухмерное сечение поверхности отклика, характеризующее зависимость равномерности распределения клубней по дну борозды после посадки от показателя кинематического режима $(\lambda)$ и диаметра катка (D) 
Анализ графических изображений двумерных сечений (рисунки 3 - 5) привел к выводу, что при параметре оптимизации (у), отвечающем за равномерность распределения картофеля по дну борозды, превышающем 86 \% оптимальные значения факторов находятся в интервалах: $14-26 \mathrm{H}$, $\mathrm{D}=115-155 \mathrm{мм}, \lambda=0,8-1,1$

Очевидно, что при инженерных расчетах уравнение (1) удобнее представлять в раскодированном виде. С учетом коэффициентов регрессии оно будет выглядеть следующим образом:

$$
\begin{gathered}
y=-25,7435+0,1343 P+1,0955 D+77,6242 \lambda+0,0035 P D+0,3775 P \lambda-0,1565 D \lambda- \\
-0,0243 P^{2}-0,0036 D^{2}-34,3334 \lambda^{2}
\end{gathered}
$$

Заключение. В результате лабораторных исследований высаживающего аппарата с ограничителем раскатывания клубней получили следующие оптимальные значения факторов, влияющих на распределение клубней картофеля при посадке: $P=14-26 \mathrm{H}$ (усилие прижатия катка к дну борозды), D = 115 - 155 мм (диаметр катка), $\lambda=0,8-1,1$ (показатель кинематического режима); при этом параметр оптимизации равномерность распределения клубней по дну борозды после посадки соответственно будет составлять не менее $86 \%$.

При использовании экспериментального высаживающего аппарата с ограничителем скорости клубней с данными конструктивными параметрами повысится урожайность производимой культуры и снизятся затраты на её производство.

\section{Список литературы}

1. ГОСТ Р 52778-2007. «Испытания сельскохозяйственной техники. Методы эксплуатационнотехнологической оценки».

2. Доспехов Б.А. Методика полевого опыта (с основами статистической обработки результатов исследований). - 5-е изд., доп. и перераб. - Москва: Агропромиздат, 1985. - 351 с

3. Халафян A.A. STATISTIC A 6: статистический анализ данных: учебник. - Москва: ООО «Бином-Пресс», 2007. - 512 с.

4. ГОСТ Р 28306-2018 «Техника сельскохозяйственная. Машины для посадки картофеля. Методы испытаний»

5. Веденяпин Г.В. Общая методика экспериментального исследования и обработки опытных данных. - М.: Колос, 1973. - 199 с.

6. Львовский Е.Н. Статические методы построения эмпирических формул. - М.: Высш. шк., 1988. -239 c.

7. Коновалов В.В. Практикум по обработке научных исследований с помощью ПЭВМ. Пенза: РИО ПГСХА, 2003 г. - 177 с.

\section{References}

1. GOST R 52778-2007. «Ispytanija sel'skohozjajstvennoj tehniki. Metody jekspluatacionnotehnologicheskoj ocenki».

2. Dospehov B.A. Metodika polevogo opyta (s osnovami statisticheskoj obrabotki rezul'tatov issledovanij). - 5-e izd., dop. i pererab. - Moskva: Agropromizdat, 1985. - $351 \mathrm{~s}$

3. Halafjan A.A. STATISTIC A 6: statisticheskij analiz dannyh: uchebnik. - Moskva: OOO «BinomPress», 2007. - 512 s.

4. GOST R 28306-2018 «Tehnika sel'skohozjajstvennaja. Mashiny dlja posadki kartofelja. Metody ispytanij»

5. Vedenjapin G.V. Obshhaja metodika jeksperimental'nogo issledovanija i obrabotki opytnyh dannyh. - M.: Kolos, 1973. - 199 s.

6. L'vovskij E.N. Staticheskie metody postroenija jempiricheskih formul. - M.: Vyssh. shk., 1988. - 239 s.

7. Konovalov V.V. Praktikum po obrabotke nauchnyh issledovanij s pomoshh'ju PJeVM. - Penza.: RIO PGSHA, 2003 g. - $177 \mathrm{~s}$.

\section{Сведения об авторах \\ Принадлежность к организации}

Бочкарев Антон Сергеевич - аспирант Федерального государственного бюджетного образовательного учреждения высшего образования «Пензенский государственный аграрный университет», Россия, г. Пенза, e-mail: bochkarev.a.s@pgau.ru.

Ларюшин Николай Петрович - доктор технических наук, профессор Федерального государственного бюджетного образовательного учреждения высшего образования «Пензенский государственный аграрный университет», Россия, г. Пенза, e-mail: larushinnp@mail.ru.

Кухарев Олег Николаевич - доктор технических наук, профессор Федерального государственного бюджетного образовательного учреждения высшего образования «Пензенский государственный аграрный университет», Россия, г. Пенза, e-mail: kucharev.o.n@pgau.ru. 


\title{
Author credentials
}

Affiliations

Bochkarev Anton - post-graduate student of Federal State Budgetary Educational Institution of Higher Education "Penza State Agrarian University”, Russia, Penza, e-mail: bochkarev.a.s@pgau.ru.

Laryushin Nikolay - Full Doctor of Technical Sciences, Professor of Federal State Budgetary Educational Institution of Higher Education "Penza State Agrarian University", Russia, Penza, e-mail: larushinnp@mail.ru.

Kuharev Oleg - Full Doctor of Technical Sciences, Professor of Federal State Budgetary Educational Institution of Higher Education "Penza State Agrarian University", Russia, Penza, e-mail: kucharev.o.n@pgau.ru.

Поступила в редакцию (Received): 11.05.2020 Принята к публикации (Accepted): 14.07.2020

УДК 631.311

DOI: $10.35887 / 2305-2538-2020-4-33-40$

\section{ПОВЫШЕНИЕ ЭФФЕКТИВНОСТИ ОБРАБОТКИ ПОЧВЫ ДЛЯ КОМБАЙНОВОЙ УБОРКИ КАРТОФЕЛЯ}

\author{
${ }^{1}$ Гаджиев Парвиз Имранович \\ ${ }^{1}$ Рамазанова Гюльбике Гудретдиновна \\ ${ }^{2}$ Манаенков Константин Алексеевич \\ ${ }^{1}$ ФГБОУ ВО «Российский государственный аграрный заочный университет» \\ ${ }^{2}$ ФГБОУ ВО «Мичуринский государственный аграрный университет»
}

Реферат. Рассматривали проблему уменьшения содержания комков в почве, с иелью подготовки ее к комбайновой уборке картофеля. Предложена почвообрабатывающая фреза с зубиеобразной формой ножа. Приведены результаты исследования влияния длины ножа фрезы, скорости вращения фрезерного барабана и числа ножей на величину крошения почвы. Предложена программа исследований с уровнями и интервалами варьирования факторов. Проведен анализ полученного уравнения регрессии, отражающего зависимость степени крошения почвы в закодированном виде от значимых факторов. Теоретические предпосылки были проверены полевыми исследованиями предлагаемой фрезы с зубиеобразным профилем ножа на полях ООО «Белая Дача Фарминг» Тамбовского района, Тамбовской области. Для испытаний выбрали поля после уборки ячменя, с помощью разработанной фрезы проводили рыхление почвы. Были получены следуюшие характеристики почвы: влажность 17 - $21 \%$, твердость - 0,8 - 1,8 МПа, плотность 0,9 - 1,0 г/см ${ }^{3}$, средняя высота растительных и пожснивных остатков - 20 см. Результать агротехнической оченки показали, что обработка почвы на глубину 11,6 см обеспечивает удовлетворительное качество крошения, плотность обрабатываемого слоя в 1,10 г/см³. Все это отвечает агротехническим требованиям созревания картофеля. Подрезаются полностью сорные растения. Высота гребней составила 1,54 - 1,62 см. В тяжельх почвах комбайны работают легче, состав вороха стал чист от комков и уменьшилось повреждение клубней. При комбайновой уборке картофеля, его урожайность на подготовленном участке, путем фрезерования выросла на $25 \%$, количество почвенных примесей в бункере снижается на $35-40 \%$.

Ключевые слова: обработка почвы, крошение, скорость вращчения фрезерного барабана, ножи с зубиеобразным профилем.

\section{IMPROVING THE EFFICIENCY OF TILLING THE SOIL} FOR COMBINE HARVESTING POTATOES

\author{
${ }^{1}$ Gadzhiyev Parviz \\ ${ }^{1}$ Ramazanova Gulbike \\ ${ }^{2}$ Manayenkov Konstantin \\ ${ }^{1}$ FSBEI HE "Russian State Agrarian Correspondence University" \\ ${ }^{2}$ FSBEI HE "Michurinsk State Agrarian University”"
}

